\section{Fifty Years of Nylon}

A hot new item appeared on the market half a century ago this year. Nylon, the first successfully produced commercial polymer fiber, made its debut in a humble fashion, used as bristles for toothbrushes. Since then, nylon has become a generic term for synthetic textile fibers made from long-chain polyamides and is used widely for a variety of common items, including industrial and commercial fabrics, guitar strings, parachutes, fish line, netting, and ropes.

After World War I, a great deal of industrial research focused on the properties and manufacture of various polymers. As early as 1913, German chemists were investigating the creation of synthetic fibers based on polyvinyl chloride, but the material properties of such fibers did not allow for textile applications. In 1928 the Germans spun fibers from a copolymer of vinyl chloride and vinyl acetate, but these also were not commercially viable.

In 1927 E.I. Du Pont de Nemours \& Co. in Wilmington, Delaware, established a fundamental research program to study the chemistry of polymers, how and why atoms or small groups of atoms would link together to form giant molecules such as those occurring naturally in rubber and silk. It was Du Pont's intention to develop and produce a completely new synthetic textile fiber different from rayon and acetate, the other manmade fibers on the market.

Textile and industrial applications of synthetic fibers did not come about until research focused on polyesters and polyamides. Polyamides had been investigated almost 30 years before, by Gabriel in 1899, but the possibilities for producing polyamide fibers were not realized until a fortunate accident at the Du Pont polymer research lab under the direction of Wallace E. Carothers.

As with many major discoveries, nylon fiber came about unexpectedly. The laboratory team had been investigating polymer chemistry for about two years when one of the researchers began work with a molten sample of a new polymer. In trying to remove a small sample from the preparation, he found that the polymer could be drawn out into a long fiber. Even after the fiber had cooled, the chemist was able to stretch the filament to several times its original length. In addition to its elastic properties, the silklike fiber was strong and lustrous. Others soon realized its commercial potential for textile use.

More years of research finally produced the first true nylon fiber in 1935, modified from the prototype condensation polymer and squirted through an improvised spinneret-a hypodermic needle! Nylon fibers first appeared on the market as toothbrush bristles in 1938. After a limited test marketing in 1939, the general U.S. public could purchase the first knitted nylon stockings on May 5, 1940. Later that year, Du Pont exhibited other nylon items at nationwide fairs.

Du Pont coined the term "nylon" in 1938. Originally, the marketers had intended to call the fiber "norun" because they thought that stockings knitted from it would be resistant to the runs that were such a bane to silk stockings. However, the sheer nylon fabric was not completely resistant to runs, and so the name turned out to be inappropriate. Next proposed was "nuron" - norun spelled backwards but $\mathrm{Du}$ Pont finally chose the term "nylon" because of its appealing and distinctive sound.

"Nylon" is a generic name for any long-chain synthetic polyamide capable of being formed into a filament in which the constituent elements are oriented in the direction of the axis. Types of nylon can be made from polymerizing nylon salt (hexamethylenediamine and adipic acid) or caprolactam.

In manufacturing nylon fiber the base molten polyamide material is cooled into flat sheets that are then cut into smaller pieces. These chips are fed into a melter where a screw carries them over a heated element, and the molten material is extruded through spinnerets to form filaments. The cooled fibers are rolled onto a retaining drum and treated with antistatic and lubricating agents to

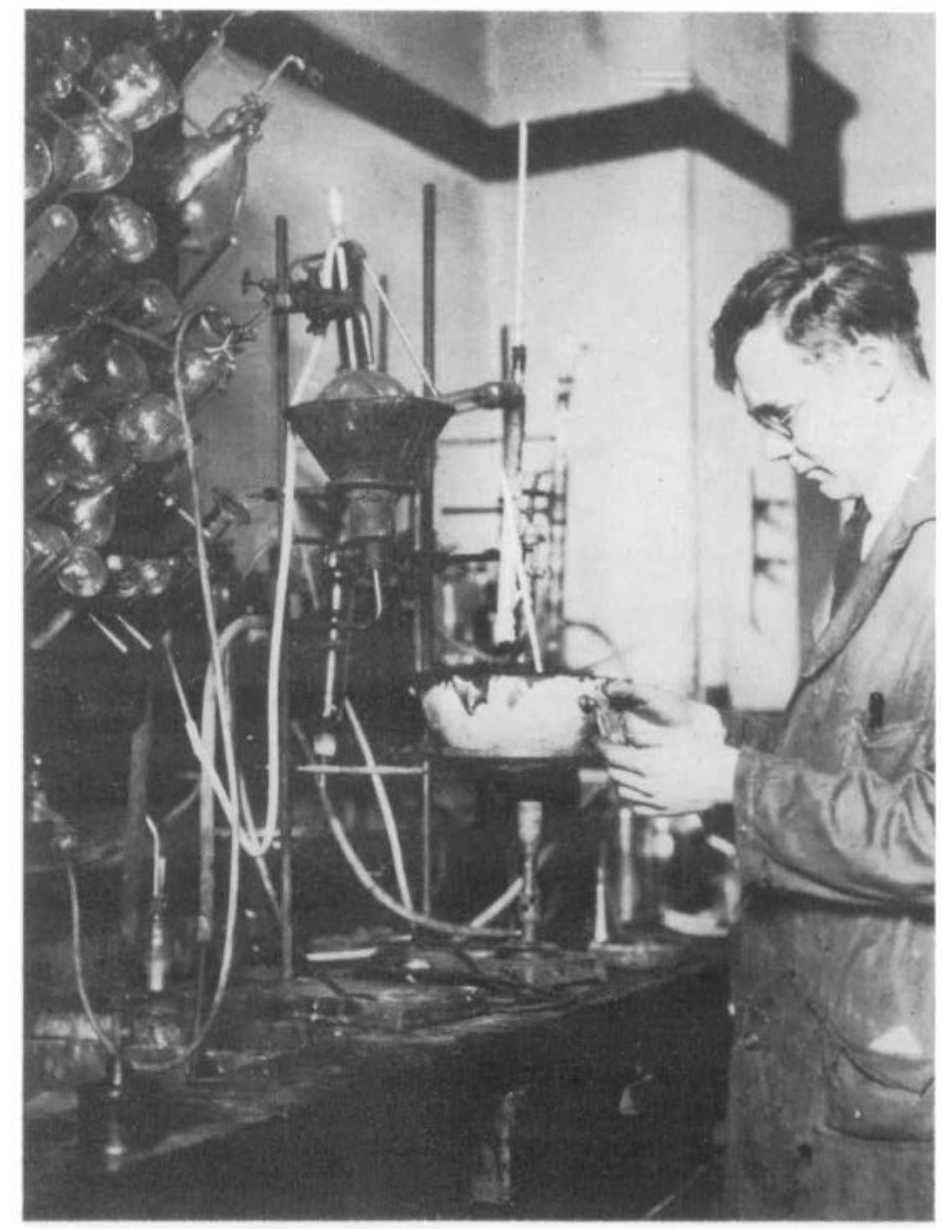

Dr. Wallace H. Carothers, the inventor of nylon, at the Du Pont Company's Experimtental Station near Wilmington, Delaware. Photo courtesy of Du Pont. 
prevent electrostatic buildup. The fiber is stretched between rollers to give it the desired balance of strength and stretch and is allowed to age on a bobbin for several days for the polymer crystallization to stop.

When the cooled fiber is drawn, it may stretch to as much as five times its original length, to where the molecules are aligned into the most efficient crystalline structure. The filament will then withstand large loads without further stretching. These lustrous and strong fibers have outstanding mechanical properties that make nylon so effective as a synthetic textile fiber. In addition to its high strength-to-weight ratio and its high abrasion resistance, nylon has a high breaking elongation and a very good recovery from deformation. Nylon is almost unaffected by water-it retains its shape and color when wet and dries quickly. Nylon fabric also resists damage from sunlight exposure. The fibers are unaffected by bacteria, fungi, and insects.

Nylon is mostly used for textiles, tire cord and strong threads, and less extensively for molded plastics. Other fibers blended with the nylon can improve the fabric's tensile strength and abrasion resistance. To the delight of manufacturers, nylon fibers can be formed into textiles resembling wool, silk, or cotton flannels or linens.

The 13 years of research and development for nylon cost Du Pont approximately $\$ 27,000,000$. During World War
II, nylon production was diverted mainly to military applications, such as camouflage fabric, netting, and parachutes. After the War, commercial uses for nylon filled many niches in everyday life. In fact, today the household word for sheer stockings has become "nylons."

In the years following World War II many manufacturers introduced new polymer fibers, such as dacron and orlon, made from polyamides, polyesters, polyvinyl chloride, polyacrylics, polyvinyl alcohol, and others. In only half a century fabrics made from new polymers have become a part of our daily life.

KEVIN J. ANDERSON

\section{AIP JOURNAL SUBSCRIPTION RATES for MRS Members}

Members of the Materials Research Society are entitled to special subscription rates on 10 journals published by the American Institute of Physics.

Applied Physics Letters

Current Physics Index

General Physics Advance Abstracts

Journal of Applied Physics

Journal of Chemical Physics

Journal of Mathematical Physics

Journal of Physical and

Chemical Reference Data

Physics of Fluids

Physics Today

Review of Scientific Instruments

\begin{tabular}{|c|c|c|c|}
\hline \multicolumn{2}{|c|}{ Domestic Rates } & \multicolumn{2}{|c|}{$\begin{array}{l}\text { Foreign Rates } \\
\text { (Including Canada \& Mexico) }\end{array}$} \\
\hline Member & Nonmember & Member & Nonmember \\
\hline$\$ 45.00$ & $\$ 425.00$ & $\$ 80.00$ & $\$ 460.00$ \\
\hline 72.00 & 390.00 & 92.00 & 410.00 \\
\hline 14.00 & 165.00 & 24.00 & 175.00 \\
\hline 90.00 & 725.00 & 130.00 & 765.00 \\
\hline 110.00 & $1,165.00$ & 160.00 & $1,215.00$ \\
\hline 55.00 & 760.00 & 70.00 & 775.00 \\
\hline 60.00 & 265.00 & 70.00 & 275.00 \\
\hline 50.00 & 665.00 & 70.00 & 685.00 \\
\hline 25.00 & 85.00 & 35.00 & 95.00 \\
\hline 33.00 & 395.00 & 53.00 & 415.00 \\
\hline
\end{tabular}

Place your subscription for any of the above journals by contacting: Subscription Department, American Institute of Physics, 335 East 45th Street, New York, NY 10017; telephone (212) 661-9404. Be sure to indicate that you are a member of MRS. 